\title{
'I Can't Meet That Deadline': Implications of New Truck Driver Hours of Service Regulations for Florida Agriculture ${ }^{1}$
}

Richard Beilock ${ }^{2}$

\section{Introduction}

In 1939, the U.S. Federal Government established regulations limiting the number of hours that truck drivers could drive and be on duty. These are known as Hours of Service Regulations (HOSR). In response to concerns about fatigue-related accidents, the U.S. Congress mandated studies in 1995 to determine how HOSR could be improved. Eight years, many millions of dollars, and over 53,000 public comments later the revised HOSR came into effect on January 4, 2004. Over $99 \%$ of all Florida produce and ornamentals shipped outside of the state are delivered by truck. Rapid and reliable transport for these highly valued perishables is essential. In this paper, the revised HOSR is described and some assessments are made of its effect on trucking.

\section{Three Categories of Time}

Both the original and revised HOSR employ three categories of time to describe a drivers activities: Off-Duty time, On-Duty time, and Driving time.

\section{Off-Duty Time}

Off-Duty time includes all time in which the driver is not responsible for the truck and is not performing any other work for the carrier. Resting in the sleeper berth qualifies as Off-Duty time. Possibly the most significant change in the regulations is the practical definition of Off-Duty time. The above definition is for the original HOSR. It is the straightforward way most people interpret being Off-Duty. Under the original HOSR, whenever a driver was not performing any tasks for the employer, he was Off-Duty. So a driver was Off-Duty when he:

- stopped for an hour to have a meal.

- took a half-hour cat nap in the sleeper.

- spent 40 minutes shopping for a present for his/her spouse at a roadside stop.

Under the revised HOSR, all three activities would count against the total amount of time a driver could work in any one day. For example, time spent in the sleeper is Off-Duty only if it is at least two hours in duration. This will be explained further under the section "The 14-Hour Daily Work Limit."

1. This is EDIS document, FE542, a publication of the Department of Food and Resource Economics, Florida Cooperative Extension Service, Institute of Food and Agricultural Sciences, University of Florida, Gainesville, FL. Published March 2005. Please visit the EDIS website at http://edis.ifas.ufl.edu.

2. Richard Beilock, Professor, Department of Food and Resource Economics, Florida Cooperative Extension Service, Institute of Food and Agricultural Sciences, University of Florida, Gainesville, FL.

The Institute of Food and Agricultural Sciences is an equal opportunity/affirmative action employer authorized to provide research, educational information and other services only to individuals and institutions that function without regard to race, color, sex, age, handicap, or national origin. For information on obtaining other extension publications, contact your county Cooperative Extension Service office. Florida Cooperative Extension Service/Institute of Food and Agricultural Sciences/University of Florida/Christine Taylor Waddill, Dean. 
Note: Off-Duty means extended time (i.e., over two hours) free of work responsibilities. A driver cannot work at another job, even one totally unrelated to trucking, and count that time as Off-Duty.

\section{On-Duty Time}

On-Duty time includes all time spent driving or performing any work-related function. This includes passive functions such as waiting for loads and sitting in the cab while a co-driver operates the vehicle.

\section{Driving Time}

Driving time includes all time driving a vehicle. Obviously, driving time is a subcategory of On-Duty time (Figure 1).

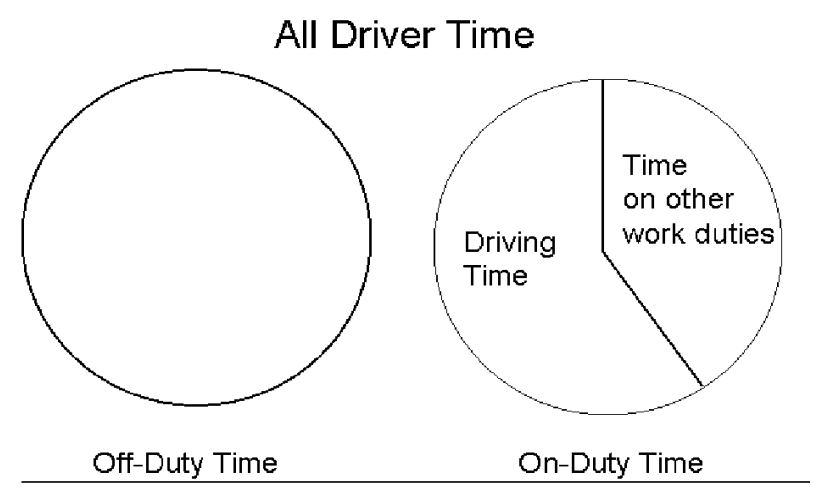

Figure 1. Driving Time.

\section{The 14-Hour Daily Work Limit}

Under the original HOSR, during any 24-hour period, a driver could not work for more than 15 hours straight. In the revised HOSR, this is lowered to 14 hours (under certain conditions, a driver is allowed to work for 16 hours, but the requirements to qualify for this exception make this rule of limited value). The impact of this seemingly minor change is magnified by the practical change in the definition of Off-Duty time. Figures 2 and 3 illustrate different working activities and how they impact the 14-hour daily work limit. Figure 2 illustrates an example of one set of activities within a 24-hour period.

Under the original HOSR, the driver would be well under the 15-hour work limit for that day. However, under the revised HOSR, the driver would be right on the edge of compliance. Figure 3

Hours counted against daily work limit Old HOSR Revised HOSR

\begin{tabular}{lll} 
Drives for 8 hours & 8 & 8 \\
Takes 1 hour for breakfast & 0 & 1 \\
Spends 2 hours unloading & 2 & 2 \\
Rests in the sleeper for 10 hours & 0 & 0 \\
Takes 1 hour for lunch & 0 & 1 \\
Takes $11 / 2$ hours for dinner & 0 & $11 / 2$ \\
Goes shopping for $1 / 2$ hour & & $1 / 2$ \\
\cline { 2 - 2 } & TOTAL hours & 14 hours
\end{tabular}

Figure 2. Original HOSR versus revised HOSR (10 hours).

illustrates what would happen under different working circumstances.

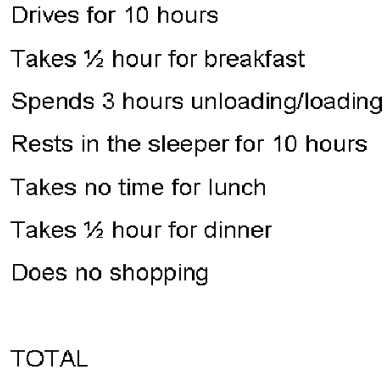

\section{Figure 3. Original HOSR versus revised HOSR (13 hours).}

Virtually everyone would agree that the workday in Figure 3 was much harder than in Figure 2. In Figure 2, the driver drove two more hours, spent an additional hour unloading, and spent three hours less eating and shopping. The greater difficulty of the activity schedule in Figure 3 is reflected in the hours counted against the daily work limit under the origina HOSR (i.e., 13 hours in Figure 3 versus 10 hours in Figure 2). However, under the revised HOSR the work hours did not change!

The United States Department of Transportation (USDOT) decided to count breaks, such as meals and shopping, against the daily work limit to force drivers to take recuperative rests rather than short breathers to "clear the cobwebs." Almost surely, USDOT also wanted to discourage drivers from claiming non-driving work activities as break-time. An example of this would be time spent waiting for an open dock space. If a driver spent an extra hour at a drop awaiting dock space, under the original HOSR, it would be easy to claim that the driver was actually 
off-duty. Under the revised HOSR, it does not matter what the driver was doing during that hour-it counts against the 14-hour daily work limit. The downside is that under the revised HOSR, a driver who is worried about staying within the 14-hour daily work limit has a disincentive to take breaks.

\section{The 11-Hour Driving Limit After 10 Hours Off-Duty}

Under the original HOSR, a driver could drive for up to 10 hours after 8 hours Off-Duty. The revised HOSR increases both the permitted Driving time and the required Off-Duty period. Now a driver can drive up to 11 hours after 10 hours Off-Duty (in adverse weather, a driver may drive for an additional two hours if he/she is within the 14 hour daily work limit and the $60 / 70$ hour, $7 / 8$ day driving limit). Off-Duty time can be one of the following:

- 10 consecutive hours with no work responsibilities.

- two periods with no work responsibilities totaling 10 hours, with each period at least two hours in duration.

Off-Duty periods may be at a location removed from the truck and workplace, such as a hotel, the driver's home, or in the tractor's sleeper. However, a rest period less than two hours is not considered to be Off-Duty. Again, time on another job cannot be counted as Off-Duty time.

\section{0- and 70-Hour Driving Rules}

Working 14 hours in a single day might not be overly tiring. But if this were done day after day, without a significant break, an individual would become fatigued. To prevent this, both the original and revised HOSR have the 60- and 70-hour driving rules:

- 60-Hour Driving Rule: A maximum of 60 hours of driving is permitted during any 7-day period. When this limit is reached, driving is not permitted until 48 hours have passed.

-70-Hour Driving Rule: A maximum of 70 hours of driving is permitted during any 8-day period. When this limit is reached, driving is not permitted until 48 hours have passed.

\section{Restarting the Clock}

An entirely new feature in the revised HOSR is the opportunity to restart calculations for the 60-Hour and 70-Hour driving rules. If a driver is Off-Duty for at least 34 consecutive hours, the number of driving hours counted against the 60- and 70-hour driving rules returns to zero. That is, after 34 consecutive hours Off-Duty, the clock is restarted for these rules.

Note: If a driver has already reached the 60- or 70-hour driving limit, he must take a full 48-hour Off-Duty time to restart the clock.

\section{Agricultural Exemption for Local Cartage}

The revised HOSR kept the agricultural exemption that eases regulatory burdens for local cartage of agricultural products and inputs. Drivers hauling agricultural products and inputs and operating within a 100-mile radius are exempt from federal work time regulations during planting and harvesting seasons. It is the responsibility of the individual states to declare when planting and harvesting seasons occur.

\section{With These New Rules, How Much Longer Will It Take to Deliver Products?}

There is no simple answer because delivery time depends upon the number of On-Duty and Driving hours the driver has accumulated, without offsetting Off-Duty hours, at the start of the journey, as well as distance. As a general rule, the impact of the revised HOSR on delivery time will not be great. Indeed, in some cases faster deliveries may be possible. Suppose the following occurred:

- the driver begins a trip fully rested.

- the truck averages 60 miles per hour.

- in addition to rest periods, the driver requires breaks for meals, fueling, etc., at a rate of three hours in every 24 -hour period. 
Table 1 illustrates the number of hours needed to travel various distances under the original and revised HOSR. For some distances, the total trip time under the revised HOSR is nearly $10 \%$ longer than it is under the original HOSR but, for other distances, the revised HOSR actually allow $6 \%$ shorter trip times. The reason for this is that both the mandatory Off-Duty times and allowable Driving times increased under the revised HOSR. In some cases, the longer Driving times reduces the number of required Off-Duty periods needed to reach a destination. For example, to travel 2,500 miles requires 42 hours of Driving time. Under the original HOSR, this could be accomplished in four 10-hour Driving periods plus one 2-hour driving period. Each of these would need to be separated by an 8-hour Off-Duty period and a total of 32 hours of Off-Duty rest during the trip. Under the revised HOSR, 42 hours of Driving time could be accomplished in three 11-hour Driving periods and one 9-hour Driving period. Each would need to be separated by one 10-hour Off-Duty period and a total of only 30 hours of Off-Duty rest during the trip. In most cases, however, the same number of rest periods is required under the original and revised HOSR. Since the rest periods are longer under the revised HOSR, total trip times tend to be somewhat longer.

Table 1. Trip times under original and revised HOSR.

\begin{tabular}{|c|c|c|c|}
\hline \multirow{2}{*}{$\begin{array}{c}\text { Distance } \\
\text { (miles) }\end{array}$} & \multirow{2}{*}{$\begin{array}{l}\text { Driving } \\
\text { Time } \\
\text { (hours) }\end{array}$} & \multicolumn{2}{|c|}{ Total Trip Time (hours) } \\
\hline & & $\begin{array}{c}\text { Original } \\
\text { HOSR }\end{array}$ & $\begin{array}{c}\text { Revised } \\
\text { HOSR }\end{array}$ \\
\hline 1,000 & 17 & 28 & 30 \\
\hline 1,500 & 25 & 46 & 51 \\
\hline 2,000 & 33 & 64 & 60 \\
\hline 2,500 & 42 & 83 & 81 \\
\hline 3,000 & 50 & 92 & 101 \\
\hline \multicolumn{4}{|c|}{$\begin{array}{l}\text { Notes: Assumes driver fully rested at start of trip, } \\
\text { average speed } 60 \mathrm{mph} \text {, with breaks for meals, } \\
\text { fueling, etc. totaling } 3 \text { hours in a } 24 \text {-hour period. } \\
\text { All estimates rounded to the nearest hour. }\end{array}$} \\
\hline
\end{tabular}

The bottom line is that the changes in trip times should not be great, from $10 \%$ longer to $6 \%$ shorter than under the original HOSR. Moreover, when there are team drivers, there will be no changes.

\section{Will the New Rules Actually Improve Safety?}

The motivation for changing the HOSR was to improve safety. USDOT estimates the revised HOSR will save 75 lives per year. Particularly, in view of the large amount of public funds that went into developing the revised HOSR and the time and trouble for industry to adapt to them, it is hoped that at least 75 people will be saved.

In the opinion of this author, however, there will be few or no positive impacts on safety. I have three reasons for drawing this regrettable conclusion:

1. As described above, the revised HOSR reduces opportunities for drivers to claim that non-driving work tasks (e.g., waiting to get a dock space) actually are rest periods. This causes drivers to rush through or skip meals and other short breaks, so safety is questionable.

2. Since there are no requirements for Electronic On-Board Recorders, handwritten logbooks will continue to be used, so there is the opportunity for falsifying information. For example, in a 2001/2002 study of long distance drivers with refrigerated rigs, it was estimated that $42 \%$ were violating HOSR or speed limits or both. Without improved systems for monitoring compliance, there is no reason to believe that the revised HOSR will be obeyed any more than was the original HOSR.

3. My final reason for believing there will be little or no improvement in safety is that USDOT has such low expectations. Between 4,000 and 6,000 people die annually in the United States in accidents involving heavy trucks. The estimate of 75 lives saved due to the revised HOSR is only between $1 \%$ and $2 \%$ of this total.

\section{Summary}

It is not surprising that the revised HOSR may yield few improvements in safety. Millions of tax dollars were expended for scientists to measure factors contributing to driver fatigue and fatigue-related accidents. This information was used in designing the new rules, but in a very political 
environment. Numerous parties weighed in to protect their interests (e.g., as mentioned before, there were over 53,000 comments submitted). While allowing everyone to voice their own view is central to our democratic system, in this case, the result has been a series of compromises that satisfy virtually no one; will cause some inconveniences to carriers, drivers, and shippers; and save few, if any, lives.

\section{References}

Beilock, R. 2003. Schedule Tightness Among Tractor-Trailer Drivers. Traffic Injury Prevention 4(2):105-112.

Federal Motor Carrier Safety Administration. 2004. HOS Frequently Asked Questions. U.S. Department of Transportation, Federal Motor Carrier Safety Administration, Washington, D.C. Available online at http://www.fmcsa.dot.gov/Home_Files/hos/ hos_faqs.asp.

Federal Motor Carrier Safety Administration. 2004. The Revised Hours-of-Service Regulations. U.S. Department of Transportation, Federal Motor Carrier Safety Administration, Washington, D.C. Available online at http://www.fmcsa.dot.gov/Home_Files/hos/ faxsheet.htm.

\section{Appendix: Data}

The 2001/2002 Driver Survey: This survey was conducted in November of 2001, and in January, March, and May of 2002. The survey sites included the Florida Agricultural Inspection Stations located on interstate highways U.S. I-10, U.S. I-75, and U.S. I-95. The drivers of 1,642 refrigerated tractor-trailers were interviewed as they exited the Florida Peninsula.

While the survey sites were all in Florida, the study has relevance for long-distance haulage throughout North America. The sample contained drivers from all 48 contiguous U.S. states and 8 Canadian provinces. These drivers were enroute to destinations in 46 states, the District of Columbia, and 7 Canadian provinces. Trip distances ranged from 100 to 3,347 miles, averaging 1,222 miles. 